\title{
O Gerenciamento da demanda de água é o caminho para propiciar a sua preservação
}

\author{
Eliete de Pinho Araújo' \\ Rodrigo Pinho Rodrigues ${ }^{2}$
}

Riane Nunes ${ }^{3}$

\section{Resumo}

É de grande importância para a Capital Federal, Brasília, Brasil, utilizar a água pluvial, já que é uma cidade de clima seco e quente. O trabalho é sobre a instalação de poços de armazenagem de água pluvial em estabelecimentos comerciais, residenciais, industriais e até hospitalares. Isso é um importante ponto de partida para planejar os futuros projetos de arquitetura relacionados aos sistemas de drenagem de água. Para que o projeto se torne possível, um sistema de canalização é planejado, utilizando sistemas de calhas instaladas ao redor da cobertura e da construção, o qual coleta a água pluvial e a direciona a um tanque instalado no jardim da casa. Esse tanque é conectado ao sistema de torneiras do jardim. Contudo, também há a opção de irrigação, utilizando água proveniente do sistema de esgoto. O projeto possui uma função muito prática: tirar vantagem dos seis meses chuvosos da Capital, armazenando o máximo de água possível nesses tanques enterrados. O projeto pode ainda utilizar água da chuva ou do esgoto, armazenada em sistemas independentes, e que, após ser tratada, tal sistema permite que esta água seja utilizada em vasos sanitários e/ou no reuso para lavagem de edifícios e estabelecimentos comerciais, industriais ou hospitalares.

Palavras-chave: Reuso de água. Eficiência. Consumo.

\section{Introdução}

São poucos os recursos essenciais à vida que estão restritos por limites de disponibilidade tão definidos. A natureza finita do recurso água contém um as-

\footnotetext{
${ }^{1}$ Professora/Mestre/Arquiteta/Doutora. Curso de Arquitetura e Urbanismo - FATECS UniCEUB. Doutorado em Saúde Pública - ENSP- FIOCRUZ, Rio de Janeiro, Brasil. (eliete_pa@yahoo.com.br)

${ }^{2}$ Estudante do Curso de Arquitetura e Urbanismo - FATECS - UniCEUB.

${ }^{3}$ Estudante de Mestrado em Arquitetura - PPE - UFRJ.
} 
pecto crítico no qual o crescimento populacional influi diretamente. A contínua urbanização aliada à elevada densidade demográfica, principalmente nas regiões metropolitanas, contribui consideravelmente para o aumento da demanda de água e para a poluição dos corpos hídricos, seja por esgoto doméstico quanto por industrial.

Desse modo, percebe-se que com uma concentração populacional cada vez maior, a disponibilidade média de água renovável por habitante tende a diminuir, fato que repercute diretamente sobre a saúde e sobre os padrões de qualidade de vida da sociedade em geral.

A crescente preocupação com a preservação de água levou autoridades e pesquisadores a desenvolverem trabalhos e pesquisas que resultaram em programas públicos de planejamento e gestão dos recursos hídricos. Assim, o previsível horizonte de sua escassez a dotou de um valor econômico e sua evidente essencialidade a induziu à normatização de seu uso, com legislação específica e atuação do poder público, dada a criação da Política Nacional de Recursos Hídricos em 1997 e da Agência Nacional de Águas em 2000. Por conseguinte, com aprovação da lei de outorga e cobrança pelo uso da água, a iniciativa privada passou a adotar medidas de racionalização e reuso da água em seus processos industriais. Mais tarde, escolas, universidades, hospitais e edifícios comerciais também passaram a aderir a esse novo sistema.

\section{0 desenvolvimento das cidades conforme a conservação dos recursos hídricos}

Em todas as regiões brasileiras já se percebem ações em prol da economia de água. A Região Nordeste, em especial os estados da Bahia, do Ceará e do Rio Grande do Norte, atualmente destacam-se pela implantação de sistemas de reuso de água na irrigação e em pequenas comunidades rurais e urbanas por meio de lagoas de estabilização para tratamento de esgoto doméstico. Em muitos casos, o benefício de programas como esse se estende além do ambiental e do econômico, pois o reaproveitamento da água gera uma nova atividade, promovendo um bem social, como foi o caso de uma comunidade no interior da Bahia que, com a implantação de sistema de tratamento de esgoto doméstico, passou a reutilizar a água 
tratada para irrigar a plantação de flores, tornando a venda das delas a principal atividade e fonte de renda daquela comunidade.

Já nas regiões Sul e Sudeste, começam a despontar, principalmente nas áreas metropolitanas, projetos de reuso de água de banho (águas cinza) em condomínios residenciais. Vale salientar que, nesse tipo de projeto, é fundamental a conscientização e o apoio dos moradores. Nesse caso, o grande preconceito da sociedade contra a origem da água de reuso, por desconhecimento ou desconfiança da mesma, infelizmente, ainda é o maior entrave ao desenvolvimento e à difusão no Brasil dessas técnicas. Segundo Oliveira Jr. (2004), nessas regiões mais desenvolvidas, industrializadas e bastante povoadas, mesmo possuindo bacias hidrográficas com grande capacidade em volume de atender a demanda de água, já estão passando por dificuldades na obtenção deste insumo: a água.

Todavia, a educação ambiental nas escolas de base é um grande exemplo de que a geração do século XXI está crescendo mais consciente de seus deveres como cidadã ao proteger e preservar a natureza de forma sustentável, vis-à-vis ao desenvolvimento econômico e à promoção do bem-estar social.

Em Brasília, além do importante trabalho realizado na área de educação ambiental nas escolas e universidades, ressalta-se a criação, em 1997, do Programa Nacional de Combate ao Desperdício de Água (PNCDA), pelo Ministério do Planejamento e Orçamento e pela Secretaria de Política Urbana (SEPURB), formado por documentos técnicos (os DTAs) que são emitidos no âmbito de três áreas: planejamento, gestão e articulação institucional das ações de conservação e uso racional da água; conservação da água nos sistemas públicos de abastecimento e conservação da água nos sistemas prediais.

Em face desse tipo de problema, para se evitar uma futura escassez, a utilização de programas de gerenciamento de água no combate ao consumo excessivo de água potável em grandes instalações prediais vem sendo adotado já em vários estados do país com resultados bastante positivos.

Atualmente, dentre os vários programas que estão sendo difundidos, podese destacar a participação pioneira do estado de São Paulo, criado em 1995, por meio de parcerias entre a Companhia de Abastecimento e as universidades. Sua importância reside na sua aplicação em grandes edifícios públicos, como hospitais, 
escolas, universidades, que vem servindo de base para outros grupos de trabalho iniciados no país.

O contraste no Brasil de inundações, secas e geadas deve ser estudado de modo a buscar soluções que possam se adequar aos problemas cíclicos de grandes estiagens do Nordeste, ou de enchentes por falta de um sistema adequado de drenagem nas cidades, aliado também ao excesso de solo impermeável em virtude da ausência de áreas verdes, do grande percentual de pavimentação com asfalto e do não cumprimento às prescrições urbanísticas de uso e ocupação do solo, promovendo altos índices de área construída nos loteamentos.

A cidade do Rio de Janeiro é um bom exemplo acerca desse assunto, visto que foi instituída recentemente, em fevereiro de 2004, uma lei que obriga todos os novos edifícios com mais de $500 \mathrm{~m}^{2}$ de área impermeabilizada a construírem reservatórios para recolhimento de água de chuva, com o objetivo de retardar temporariamente o escoamento para a rede de drenagem. Além disso, os depósitos servirão como estímulo para o reaproveitamento da água em diversos usos, como rega de canteiros e jardins, lavagem de carro, calçadas e play ground, no abastecimento de piscina e, principalmente, em instalações sanitárias. O município ainda estabelece que as novas construções não terão o habite-se, caso não apresentem um sistema que capte água em áreas como telhados, terraços e coberturas. A medida também é obrigatória no caso dos novos prédios residenciais com 50 ou mais unidades.

Em Curitiba, foi sancionada uma lei em setembro de 2003 que criou no Município um Programa de Conservação e Uso Racional da Água nas Edificações, chamado PURAE. O PURAE tem como objetivo instituir medidas que induzam à conservação, uso racional e utilização de fontes alternativas para captação de água nas novas edificações, bem como a conscientização dos usuários sobre a importância da conservação da água. Tal lei recomenda também que os sistemas hidráulicosanitários das novas edificações deverão ser projetados visando ao conforto e à segurança dos usuários, bem como à sustentabilidade dos recursos hídricos.

Dentre as ações de utilização de fontes alternativas compreendidas na lei municipal de Curitiba, destacam-se a de captação, armazenamento e utilização de água proveniente das chuvas e de águas servidas, visto que isso obriga todos os novos condomínios residenciais a incorporarem essas ações em seus projetos de 
construção para múltiplos usos em substituição à cara água potável. No caso específico dos sanitários, que consomem em média 70\% de toda a água numa construção, a lei torna obrigatória a canalização das águas usadas na lavagem de roupas, chuveiros ou banheiras para uma cisterna, onde serão filtradas e posteriormente reutilizadas nas descargas sanitárias. Então, somente depois, essa água seria descartada para a rede de esgoto.

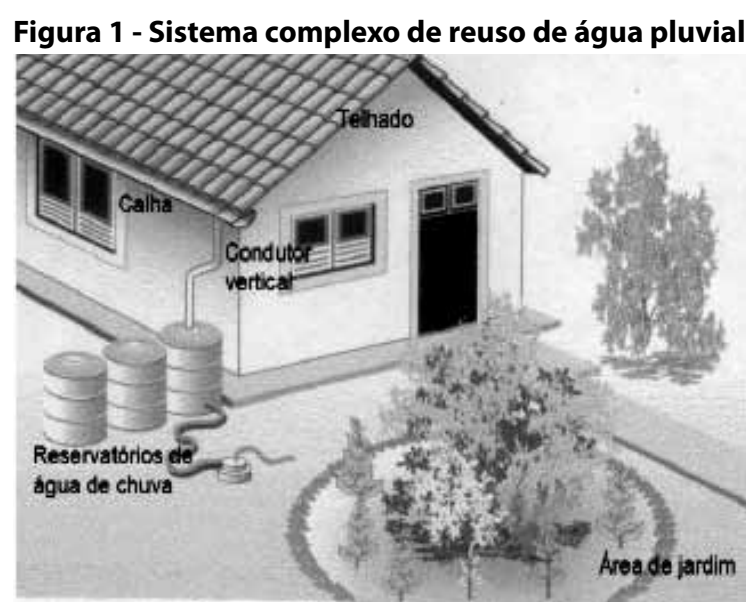

Fonte: WATERFALL apud MAY (2004)

Figura 2 - Sistema de grade localizada sobre a calha

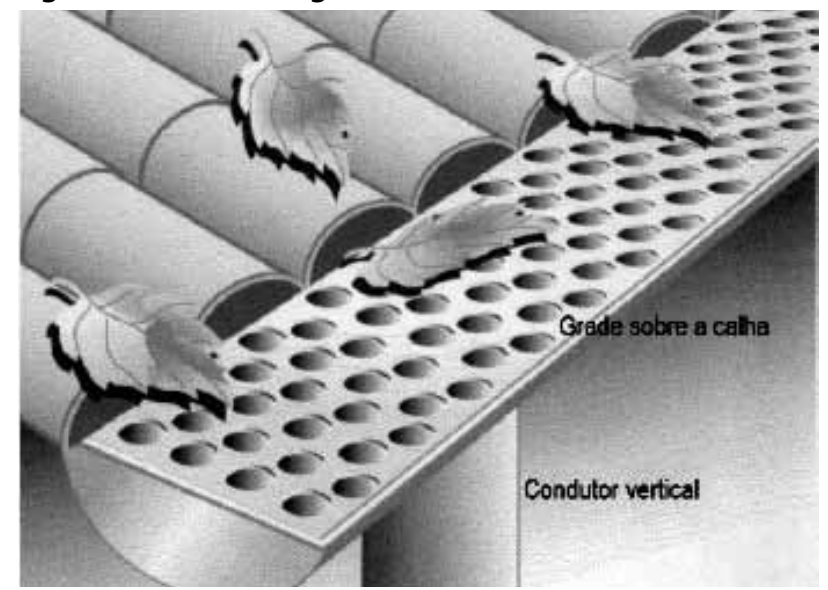

Fonte: WATERFALL apud MAY (2004). 
Figura 3 - Sistema simples de reuso de água pluvial

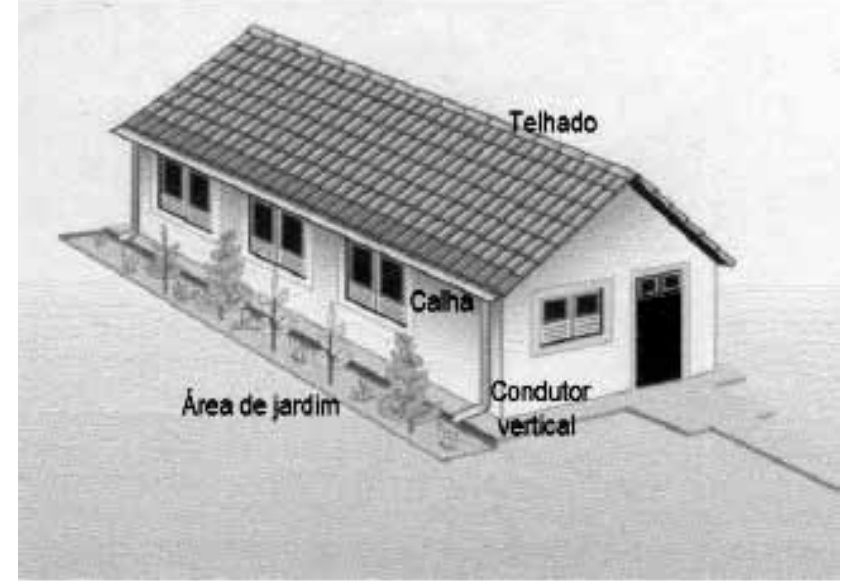

Fonte: WATERFALL apud MAY (2004)

Outro aspecto importante da nova lei diz respeito à instalação obrigatória de hidrômetros individuais nas novas edificações, evitando-se, assim, que o consumidor que desperdiça água se beneficie da conta pelo condomínio, prejudicando quem

Figura 4 - Reservatório de auto-limpeza com torneira de bóia

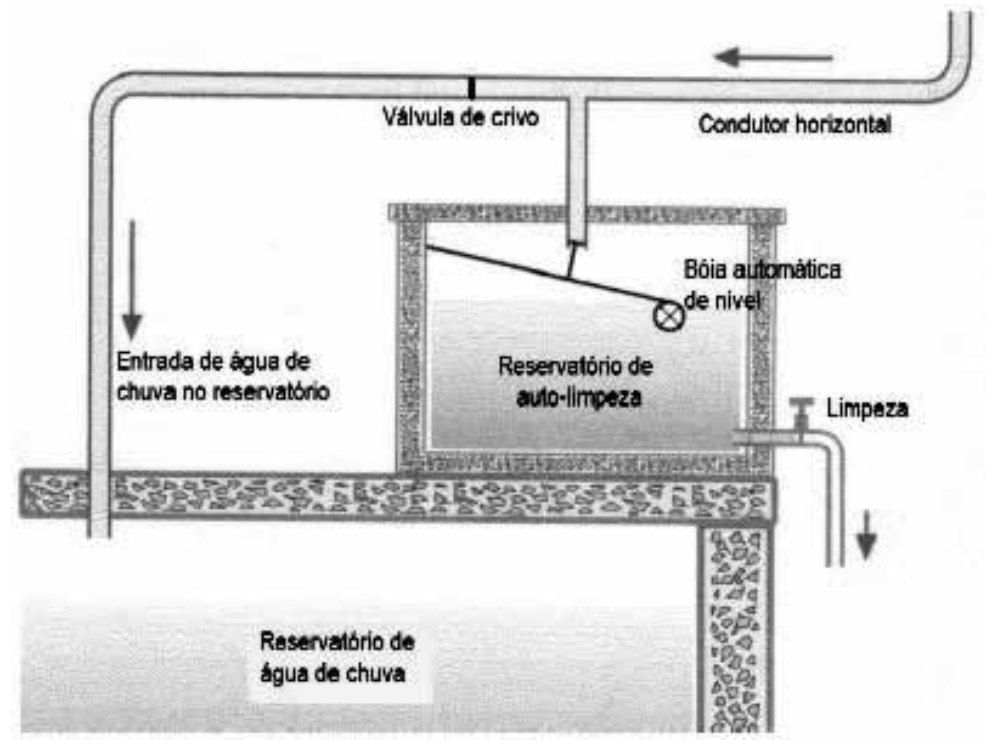

Fonte: DACACH apud MAY (2004). 
já aprendeu a economizar. A norma torna ainda obrigatório o uso de aparelhos eficientes como vasos sanitários, torneiras e chuveiros que possuam dispositivos economizadores de água.

Há também registradas outras iniciativas por parte do poder público no semi-árido nordestino, a fim de universalizar o acesso de água potável nas comunidades mais carentes. Podemos citar a construção das adutoras no Estado do Rio Grande do Norte, das técnicas de captação de água de chuva e armazenamento em cisternas e a contribuição da Petrobrás na perfuração de poços, entre outros.

\section{A necessidade de preservação frente ao aumento contínuo do consumo de água}

As ações focadas no meio ambiente compreendem uma extensão bem maior do que simplesmente a preservação e o uso eficiente dos recursos naturais. O caráter holístico no qual o assunto água está inserido necessita tanto de medidas político-administrativas quanto socioeconômicas e ambientais, o que torna ainda mais complexas as resoluções a seu respeito. Por exemplo, a eficácia de uma campanha educacional para uso racional da água numa comunidade não pode ser garantida se esta não possui um bom sistema de abastecimento d'água e de tratamento de esgoto, pois a sua ausência acarreta a contaminação dos corpos hídricos. Assim, de nada adiantaria a redução do consumo se as fontes de água ficassem contaminadas.

Para tanto, ressalta-se a importância de ações conjuntas do poder público frente à sociedade e aos órgãos administrativos responsáveis pelo saneamento, abastecimento e limpeza urbana das cidades. Deve-se também exigir a extinção dos lixões e a efetiva instalação de aterros controlados, para evitar a contaminação das águas subterrâneas (lençóis freáticos) e a proliferação de vetores causadores de doenças e agravos à saúde humana.

Independente do local no qual o recurso hídrico esteja inserido, é notório que ele desempenha diferentes funções dentro do nosso ciclo de vida: primeiramente, como produto para o consumo direto dos seres humanos; segundo, como matéria-prima para diversas atividades, processos e/ou serviços e, por último, como própria constituinte dos ecossistemas. 
Assim, a água é reconhecida por portar valor econômico, estratégico e social essenciais à existência e bem estar do homem e à manutenção dos ecossistemas do planeta. É, portanto, um bem comum a toda a humanidade e a sua utilização deve implicar em respeito à lei. A sua proteção deve constituir uma obrigação jurídica para todo homem ou grupo social que a utiliza. Essa questão não deve ser ignorada nem pelo homem nem pelo Estado. O equilíbrio e o futuro de nosso planeta dependem da preservação da água e de seus ciclos que devem permanecer intactos e funcionando normalmente para garantir a continuidade da vida sobre a Terra.

O gerenciamento do consumo das águas doces superficiais e subterrâneas é que deve ser o grande foco de ação, visto que a população mundial tenderá sempre a crescer e os recursos hídricos irão permanecer continuamente inalterados. Dessa forma, governo, instituições privadas e cidadãos devem agir em conjunto por meios de programas, de campanhas e da participação efetiva e consciente de todos em prol da redução do consumo de água e do bem estar comum das sociedades atuais e futuras.

\section{Considerações finais}

A importância da conscientização em reduzir o consumo de água reside não somente na preservação dos recursos hídricos, como também na promoção da qualidade de vida de seus usuários e do contínuo desenvolvimento científicotecnológico e econômico, possibilitando a plena execução das atividades de uma localidade qualquer, independentemente do seu porte ou região.

Todavia, a eficácia de planos de racionalização do uso da água está diretamente ligada à realização de campanhas educativas que promovam o empenho e a conscientização da população que usufrui do recurso, seja no seu local de trabalho ou no seu próprio lar.

Por fim, faz-se necessária ainda uma visão mais ampla acerca do problema de desperdício de água, já que somente a implantação de novas tecnologias não basta e sim uma mudança de paradigma na cultura da sociedade brasileira. 


\section{The management of the water demand is the way to propitiate it's preservation}

\section{Abstract}

Inasmuch as it is a hot and dry city, the usage of rain water is crucial to the capital city of Brazil, Brasília. This paper is about rain water well installation in commercial, residential, industrial and even hospital establishments and it is an important starting point to plan future architecture projects related to drainage water systems. In order for the project to work, a plumbing system is planned using a web system installed around the roof which collects the rain water and directs it to a tank installed in the house yard. This tank is connected to the yard tap system. However irrigation is also possible by using the water from the sewer system. The project has a very practical aspect: to take advantage of the six rainy months of the Capital, storing as much water as possible in these underground tanks. The new projects may use rain or sewer water, stored in independent systems which, after being treated, provide water to be used in toilets and/or reused in the washing of buildings, commercial establishments, industries and hospitals. Taps which reduce the water consumption up to $55 \%$ are being installed in restrooms of some buildings. Toilet valves are also being substituted for more modern models which reduce consumption in $80 \%$.Other systems of rain water and even the treated sanitary sewer water reuse are water usage in general washing and cleaning, toilets watering, garden irrigation, fire systems, hot water, air conditioning and civil construction.

Keywords: Water reuse. Efficiency. Consumption.

\section{Referências}

GONÇALVES, O. M. et al. Programa Nacional de Combate ao Desperdício de Água: DTA B3 - medidas de racionalização do uso da água para grandes consumidores. Brasília: Ministério do Planejamento e Orçamento; Secretaria de Política Urbana, 1999.

OLIVEIRA JR., Osvaldo B.; SILVA NETO, Jorge V. Utilização de sistema de coleta de esgoto sanitário a vácuo, com bacias de volume ultra-reduzido, em um edifício comercial na cidade de São Paulo. In: CONFERÊNCIA LATINO-AMERICANA DE CONSTRUÇÃO SUSTENTÁVEL, 1., 2004, São Paulo; ENCONTRO 
NACIONAL DE TECNOLOGIA DO AMBIENTE CONSTRUÍDO, 10., 2004, São Paulo. Anais... São Paulo, 2004.

OLIVEIRA, Lúcia Helena de. Metodologia para implantação de programa de uso racional da água em edifícios. 1999. Tese (Doutorado em Engenharia) -Escola Politécnica da Universidade de São Paulo, São Paulo, 1999.

PARANÁ. Lei $n^{\circ} 10.785$, de 18 de setembro de 2003. Cria no Município o Programa de Conservação e Uso Racional da Água nas Edificações - PURAE. Curitiba, 2008. Disponível em: <http://domino.cmc.pr.gov.br/contlei.nsf/ 735cd5bfbla32f34052

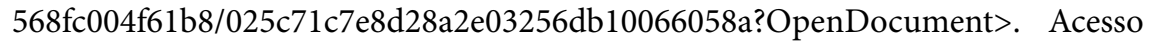
em: 08 maio 2009.

RIO DE JANEIRO (Estado). Decreto n 23.940, de 02 de fevereiro de 2004. Dispõe sobre a Criação de Sistema de Captação de Água da Chuva em Edifícios no Município. Disponível em < http://www.rio.rj.gov.br/smac/up_arq/DEC-2394004-aguaspluv.pdf $>$. Acesso em maio 2008.

SILVA, Gisele S. et al. Implantação de Programas de Uso Racional da Água em Campos Universitários. In: CONFERÊNCIA LATINO-AMERICANA DE CONSTRUÇÃO SUSTENTÁVEL, 1., 2004, São Paulo; ENCONTRO NACIONAL DE TECNOLOGIA DO AMBIENTE CONSTRUÍDO, 10., 2004, São Paulo. Anais... São Paulo, 2004.

SILVA, Ricardo T.; CONEJO, João Gilberto L.; GONÇALVES, Orestes M. Programa Nacional de Combate ao Desperdício de Água: DTA A1 - Apresentação do programa. Brasília: Ministério do Planejamento e Orçamento; Secretaria de Política Urbana, 1998.

UNIVERSIDADE DE CAMPINAS (UNICAMP). PRÓ - ÁGUA. Programa de Conservação de Água da Universidade Estadual de Campinas. Disponível em: <www.fec.unicamp.br/ milha/proagua.htm>. Acesso em: ago. 2004.

UNIVERSIDADE DE SÃO PAULO (USP). Programa de Uso Racional da Água PURA. Desenvolvido pelo Laboratório de Sistemas Hidráulicos Prediais da Escola Politécnica da Universidade de São Paulo. Disponível em: <www.pura.poli.usp. br>. Acesso em: ago. 2004. 